\title{
Kara Ayna Dizisi “Hemen Döneceğim” İsimli Bölümün Kayıp ve İnkar Çerçevesinde Ele Alinmasi
}

\author{
Gizem Sarısoy* \\ Orta Doğu Teknik Üniversitesi
}

\begin{abstract}
Özet
Kara Ayna dizisinin “Hemen Döneceğim” isimli bölü mü eşini trafik kazasında kaybeden Martha'nın teknolojik bir uygulama ile sanal olarak eşi Ash ile görüşmesinin yas sürecine etkisini ele almaktadır. Dizin in amac1 teknolojik ilerlemenin karanlık tarafı ile izleyiciyi yüzleştirmek olsa da yas sürecinde inkarın rolüne dair de bölümden önemli çıkarımlar yapılabilmektedir. Eşini kaybetmesinin ard ından yas süreci normal seyrinde devam ederken Martha bir teknolojik uygulama yardımı ile önce sanal olarak Ash'i taklit eden bir yazılımla yazış maya, ardından da sanal olarak Ash ile telefonda konuşmaya başlar. Martha'nın satın aldı̆̆ı uygulamanın yeni versiyonunda ise eve Ash'in sentetik olarak tasarlan mış vücudu gelir. Martha iç in bu süreç hem özlemini duyduğu eşine kavuşma, hem de sahip olduğu Ash'in gerçek Ash olmadığı gerçeği ile tekrar tekrar yüzleşme kısımlarından oluşur. Sevilen kişinin kaybının ardından kısmi inkar normal yas sürecinde de görülmesine rağmen, inkarın devam etmesi yas sürecini sekteye uğratmakta ve süreci komplike hale getirebilmektedir. Dizide işlenen bu hikaye örüntüsü sevilen kişinin kaybı ve yas sürecinde inkar çerçevesinde ele alınmıştır.
\end{abstract}

Anahtar Kelimeler: Kara Ayna dizisi, Kayıp, Yas, İnkar 


\section{Dizi ve Bölüm Bilgisi}

\section{Bölümün Künyesi:}

Dizinin adı: Black Mirror- Kara Ayna

Sezon/ Bölüm: 2. sezon 2. Bölüm

Bölüm adı: Be Right Back- Hemen Döneceğim

Yönetmen: Owen Harris

Yayın Yılı: 2013

Senaryo: Charlie Brooker

Oyuncular: Hayley Atwell, Domhnall Gleeson, Claire Keelan

Tür: Dram, bilim kurgu

Süre: $48 \mathrm{dk}$.

Kara Ayna dizisi 2011 yılında yayınlanmaya başlamıştır. Toplamda 3 sezon olan dizinin, her bölümü birbirinden bağımsız üç bölümden oluşmaktadır ve bölümler 50 dakika ile 60 dakika arasında değişmektedir. Dizi izleyiciye temelde hayatın ve teknolojinin karanlik tarafinı ele alan bir distopya sunmaktadır.

\section{Bölüm İçeriği:}

Ash ve Martha evli, genç bir çiftir. Şehirden kasabaya taşınmaya karar vermişlerdir. Dizinin başında Ash'in siklıkla telefonuna daldığına özellikle dikkat çekilmektedir. Eşya taşımak için kiraladıkları kamyonu teslim etmeye gidecekleri gün Martha'nın işi çıkmış ve Ash tek başına teslim etmeye gitmek durumunda kalmıştır. Gün içinde çalışmaya dalan Martha, akşam olmasına rağmen dönmeyen Ash'i merak etmiş, öğlen 2 'de teslim edilmesi gereken kamyonun teslim edilip edilmediğini öğrenmek için kiralama şirketini aramıştır. Kamyonun teslim edilmediğini öğrendikten bir süre sonra aklında kötü düşüncelerle kız kardeşi ile konuşurken sağlik görevlileri kapıda belirmiş ve Ash'in ölüm haberini getirmişlerdir.

Ash'in cenazesinde Martha'nın bir arkadaşı olan Sarah ona ölmüş kişilerin özelliklerini taklit eden ve böylelikle onlarla konuşuyormuş illüzyonu yaratan yeni bir teknolojiden bahsetmiştir. Bunu duyduğunda dehşete düşen Martha Sarah’yı daha fazla dinlemek istememiş ve Sarah'ya öfke ile bağırmıştır. Ash ile birlikte yerleşecekleri kasaba evinde kalmaya karar veren ve oraya çeki düzen veren Martha bir gün yatağında bilgisayar başındayken Sarah'nın onu sisteme kaydettirdiğine dair bilgi edinir ve ardından da Ash ismi ile sistemden mesaj alır. Başta Sarah'yı arayarak öfkesini dile getiren Martha günlük yaşamına dönmeye çalısır. Kusmalarının olması ile gebelik testi yapan Martha hamile olduğunu öğrenir. Hemen kz kardeşini arayan Martha ona ulaşamayınca bilgisayarın başına geçer ve sistemden Ash'le yazışmaya başlar. Martha yazışma sonrası hamile olduğunu öğrendiğinde düştüğ̈̈ dehşet ve şaşkınlıktan kurtulmuştur. Sisteme Ash'in tüm sosyal medya bilgilerini, video ve fotoğraflarını yükler ve telefonda da Ash ile konuşabilir hale gelir. Tüm gününü kulağında kulaklık Ash ile konuşmakla geçiren Martha, zaman içerisinde bu konuşmalardaki sanal kısımları da garipsemeye başlar. Bir gün telefonunu elinden düşürmesi ile Ash'i kaybedeceğinden çok korkar ve Ash ona bu uygulamada pahah ama daha ileri bir düzey olduğunu anlatrr. Sonrasında ise eve sentetik bir vücut gelir. Sentetik Ash'in aktifleştirilmesi Martha için korkutucu olmuştur. Kayglı biçimde beklerken gördüğümüz Martha üst kata aktivasyonun bitip bitmediğine bakmaya gittiğinde Ash ile karşlaşır. Bir süre Ash'in yanına yaklaşamaz ve şaşkınlığını üzerinden atamaz. Yavaş yavaş Ash'e 
yaklaşmaya başlayan Martha gerçek Ash'de olan ama sentetik Ash'de olmayan ayruntıları fark etmeye ve bunlardan rahatsılık duymaya başlar. Ash sürekli yanındaymış gibi olsa da Martha zaman zaman Ash'in uyumamasindan, nefes almamasindan ve yemek yememesinden ürkmektedir. Ne dese onu yapan Ash, Martha'nın tanıyıp bildiği Ash değildir. Onun bir kişiliği, geçmişi yoktur. Bu durum onu çileden çkarır ve Ash'den kurtulmaya karar verir. Ona uçurumdan atlamasını söyler ama son sahnede sentetik Ash'i tavan arasına kaldırdığını görürüz.

Ölüm insan için hep zor bir kavram olmuştur. Hem farkında olunan, hem farkındaliktan itilen ama yine de orada olduğu hep bilinen bir kavramdır. Felsefe ve psikolojide de ölüm kavramı sıkça irdelenmiş ve farkh görüşler ortaya atılmıştır. Martin Heidegger (1926) ölümün insan yaşamını daha anlamlı bir var oluşa sevk ettiğini belirtmiştir. İnsanların iki şekilde yaşadığını ileri sürmüştür. Birincisi var olmayı unutma durumudur. Bu durumda kişi kendisini dünyanın günlük, sıradan işleri ile oyalamaktadır. Kendi dünyasının ve hayatının sahibi olduğunun, bunu değiştirme gücünün de kendisinde olduğunun farkında değildir. İkincisi ise var olmayı düşünme durumudur. Bu durumda ise kişi var olmanın ve kendi smırlılıklarının farkındadır. Var olma ve yok olma düşünceleri ile yüzleşmiştir ve bunlarla ilgili endişeleri vardır. Heidegger'e göre ilk durumdan ikinci duruma geçmek için ölüm önemli bir deneyimdir. Birçok farkh yazar da ölümün yaşamı, yaşamın ölümü anlamlı kıldı̆̆nı öne sürmektedir. Ölüm ve yas üzerine önemli teorisyenlerden biri olan Elisabeth Kübler-Ross (1997) ölümün gerçekliğine vurgu yapmakla birlikte, hayatın içinde olmanın, doyasıya yaşamanın da ölümü anlamlı kılabileceğine işaret etmektedir. Başka bir deyişle ölüm en korkunç ve en kötü deneyim olarak görülse de aslında ölümün yaşama kattığı anlamı savunan görüşler de çoğunluktadır.

Birçok görüş geçmişte ölümü yaşamın kaçmılmaz bir parçası olarak kabul eden toplumumuzun teknolojinin ilerlemesi ve şehirleşme ile zaman içerisinde ölümü inkar eden bir topluma doğru evrildiğine odaklanmaktadır. Robert J. Lifton Death in Life: Survivors of Hiroshima isimli kitabında insanlı̆̆ın ölümle başa çkmakta giderek zorlanmasını çeşitli faktörlere bağlamaktadır (Freeman, 2005, s.8) Bunlardan ilki zaman içerisinde artan şehirleşmedir. İnsanlar doğadan gittikçe uzaklaşmış ve ölüm ve yaşam döngüsüne nadiren şahit olmaya başlamışıtır. İkinci olarak modern toplumlarda yaşlılar ve ölmekte olan kişiler gittikçe toplumun dışına itilmiştir. Bakım evleri ve hastanelerde tutulan bu kişiler insanların yalnızlık ve terk edilme korkularını da arttırmıştır. Üçüncü olarak geniş ailelerden çekirdek ailelere geçiş yaşanmış, yaşlanan ve hayatının sonuna gelen aile bireyleri ile aynı ortamda yaşama sıklığ azalmıştır. Bunun sonucu olarak da ölüm deneyimi hayatın doğal bir parçası olarak görülmekten uzakta kalmıştır. Dördüncü olarak sekülerleşme ile ölüme atfedilen anlam bulanıklaşmıştır. Beşinci olarak tıbbi anlamda meydana gelen gelişmeler insanlarda sahte bir kontrol hissi meydana getirmiş bu da insanın yaşam ve ölüm üzerinde daha çok kontrol hissetmesine neden olmuştur. Son olarak kitlesel ölümler insanların bireysel ölüm algılarını bulanıklaştırmıştır.Literatürde ölümü hayatın doğal bir parçası olarak görenlerin diğer kişilere kıyasla daha yüksek iyi oluş puanlarına sahip oldukları ve hayatta daha çok anlam buldukları belirtilmektedir (Wong ve ark., 1994). Lifton'un siraladığı tüm bu değişiklikler Wong ve ark. (1994)' nın bulguları 1şı̆̆ında değerlendirildiğinde ölümün giderek kaçınılan, dışlanan bir hal almasının insanların uyumlarına ve psikolojik sağliklarına olumsuz etkisi olabileceği düşünülmektedir.

Sevilen kişinin kaybı da hayatta karşlaşılan en zor yaşam olaylarından birisi olarak görülmektedir (Prigerson ve ark., 2009). Yapılan çalısmalarda yas belirtilerinin en şiddetli olarak çocuk kaybında, sonrasında ise eş kaybında görüldüğü belirtilmektedir (Boyraz, Horne ve Waits, 2015). Bu tür kayılara verilen tepkiler kişiden kişiye değişmektedir. Kayp yaşayanlardan bazları kayıp karşısında nispeten daha az tepki verirken, kayıp yaşayanların \%10 ila 15 ' $\mathrm{i}$ ise ciddi düzeyde stres yaşamakta ve kaybı kabullenmekte zorlanmaktadırlar (Bonanno, 2004). Farklı kişilerin ölüm karşısında farklı tepkiler vermesi literatürde çeşitli değişkenlerle ilişkili bulunmaktadır. Bu değişkenler arasında kişinin bağlanma stilleri, baş etme mekanizmaları, sosyal destek ağı, kaybedilen kişi ile ilişkisi ve yakınlı̆̆ı, kaybedilen kişinin yaşı ve kişinin 
ölüm algıs1 sayllabilir (Mancini ve Bonanno, 2009; Neimeyer, Baldwin ve Gillies, 2006; Boyraz, Horne ve Waits, 2015). Kayıp ve yas sürecini anlamakta bağlanma teorisine skklikla başvurulmaktadır. Bowlby (1973) bağlanmayı daha güçlü ve bilge olarak görülen, bazı belirli ve tercih edilen kişilerle yakınlık elde etme ve yakınlığı sürdürme davranışları olarak tanımlamaktadır. İnsan ve diğer birçok canlı hayatta kalabilmek için korunma ve bakıma ihtiyaç duymaktadır. Bebekler bağlanma figürleri yakınlarındayken ihtiyaçlarının karşılanacağını bilirler ve güvende hissederler. Fakat bağlanma figürleri ortada olmadığında bu durum ağlama, bağırma gibi tepkilerle protesto edilir ve yakınlik tekrar kurulmaya çalısılır. Eğer ayrı kalınan süre uzarsa kayg, öfke gibi tepkiler üzüntü ve kedere dönüşür. Bu tepkiler yetişkinlerin ayrılık ve ölüme bağlı kayba verdiği tepkilerle de büyük oranda benzerlik göstermektedir.

Kayıptan sonra kişilerin geçtiği aşamalara dair birçok görüş vardır. Bu görüşler içerik olarak bazı noktalarda ayrışsalar da teorisyenler herkesin yasını kendine özgü tuttuğu ve aşamaların doğrusal bir şekilde ilerlemediği konusunda hemfikirdir. Yasın evrelerinden en çok bileneni Elisabeth Kübler-Ross (1997)'un tanımladığ 1 beş aşamadır.Bu evreler hem ölmekte olan kişinin hem de yas yaşayan kişilerin yaşadığı süreci anlamakta kullanılmaktadır. Birinci evre "inkar ve yalitlanma" evresidir. Bu evrede uyuşukluk ve duyguların hissedilememesi yas yaşayan kişinin gerçekliğin fazlaca ağır yükü altında ezilmesinden onu koruma işlevi görür. İnkar da bu aşamada genellikle geçici bir savunmadır. Kısa bir süre içinde kısmi kabullenmeye dönüşür. İkinci evre "öfke" evresidir. Bu evrede öfke durumu değiştirememeye ya da kontrol edememeye karşı olabilir. Bu evrede öfke başka kaynaklara da yönlendirilebilir (doktor, sağllk personeli gibi). Üçüncü evre "pazarlik" evresidir. Bu evrede kişi kayıptan kaçınmak için çeşitli çabalara girişebilir (kötü davranışları değiştirmek için sözler vermek gibi). Dördüncü evre "depresyon" evresidir. İnkarm artık sürdürülemediği, gerçeğin ortada olduğu ve öfke ve pazarlığın işe yaramadığının farkına varıldığı noktada kişi depresif hisseder. Son aşama "kabul" evresidir. Bu evrede kişi artık gerçekle yüzleşir. Kayp yaşayan kişinin ölen kişiden aşırı duygusal iniş çıkşları olmadan konuşabilmesi kabulün bir göstergesi olabilir. Bu aşamada hayatın devam ettiğine dair bir kabul vardır ve enerji başka yerlere yatıılmaya hazırdır. Yasın aşamalarını farklı teorisyenler farkh isimlendirse de (bkz. Parkes ve Weiss, 1983; Worden, 1991; Bowlby, 1980) yasin çözümlenmesinde birçok teori ölümün gerçekliğinin kabul edilmesi ve ölmüş kişiye yapılan yatırımın başka kaynaklara yönlendirilebilmesinin önemini vurgulamaktadır.

Kübler-Ross'un aşamalarında da görüldüğü gibi kayba verilen ilk tepkiler arasında inkar vardır. Ölen kişinin olmadığını kabul edememe, yemek hazırlarken ona da tabak çıkarma, eşyalarını atamama, kapı çalınca onun geldiğini düşünme sevilen kişinin kaybından sonra sıklkla oluşan durumlardır. Bazı kültürlerde ölünün ölmemiş gibi giydirilmesi, makyaj yapılması gibi ritüeller yer alırken, bazı kültürler ise kalanların ölüm gerçeği ile yüzleştirilmesine daha çok odaklanılmıştır. Bizim kültürümüzde de ölen kişinin yakınlarına gösterilmesi, kişi gömülürken en yakınlarının ölünün üzerine toprak atması, ölen kişinin ayakkabılarının ev dışına konulması, eşyalarının dağtılması, cenazeden sonra helva yapılarak dağtılması gibi ritüeller kalanların ölümle yüzleşmesine ve inkara saplanmamasına hizmet eder görünmektedir. Ölümden sonraki ilk haftalarda ölümün inkar edilmesi normal karşlanırken, yas evrelerinde ilerleyememe, ölen kişiyi canlı tutmaya çalş̧ma, onun odasını müze haline getirme, eşyalarını atamama gibi belirtiler normal yas sürecinin dışıa çıkıldığının işareti olabilir. Patolojik yas, komplike yas, anormal yas, atipik yas, çözümlenmemiş yas, travmatik yas gibi birçok terimle ifade edilmeye çalş̧lan, normal yas sürecinin sekteye uğradığı durumlar kişinin kayıptan sonra yaşamına devam etmesine engel olabilir. Herkesin yas süreci ve bu süreçte hangi hızla ilerleyeceği birbirinden farklı olsa da zaman içerisinde kişilerin eski işlevsellik düzeylerine dönmeleri ve çevreye duygusal yatırımlarını sürdürmeleri beklenir. İnançları, tutumları, hayata bakışları kayıptan sonra değişim gösterse de birçok kişi yas sürecinin başarılı bir biçimde üstesinden gelebilmektedir. İyileşmenin sağlanabilmesi için kaybın acısının yaşanması gerekmektedir. Yasın çözümlenmesi ölen kişinin içsel bir temsilini tutmayı gerektirir. Yas çözümlendiğinde kişi yatırım yaptığı ilişkiden artık yatırımını çeker ve başka ilişkilere yatırım yapabilir. Ayrıca yası çözümleyen kişi kaybedilen kişi ile ilişkisinin her zaman 
kimliğinin bir parçası olacağının farkındadır (Humphrey ve Zimpfer, 2008). Komplike yas ise yoğun ve uzun süren, kalan kişinin hayatıı ele geçiren türden bir yastır. Kayıp yaşayan kişiler sevdiklerinin öldüğünü bilirler fakat savunmacı bir biçimde bunu inkar edebilirler. Araştırmalar yas yaşayan kişilerin \% 10 ila 20'sinde komplike yasin meydana geldiğini göstermektedir (Middleton, Burnett, Raphael, ve Martinek, 1996). Komplike yas için risk faktörleri arasında beklenmeyen ya da şiddet sonucu ölüm, sevilen kişinin intiharı, destek sistemlerinin eksikliği, çocuk tacizi ya da kötüye kullanımı öyküsü, çocuklukta ayrılma kaygısı öyküsü, kaybedilen kişi ile aşırı derecede bağımlı ilişki, ölüme hazırlıklı olmama, düşük baş etme becerileri ve düşük dayanılılı yer almaktadır (Rainer, 2013).

Yas döneminde verilen tepkilerin hangi noktada normal olmaktan çıacağına dair çeşitli görüşler mevcuttur. Yasın tanı ve smıflandırmada aldığı konum da zaman içerisinde değişmiştir. Tanı Ölçütleri Başvuru El Kitabının dördüncü ve beşinci basımları arasında değişim gösteren ve en çok tartş̧ılan noktalardan birisi de yas ile ilgilidir. DSM-IV-TR (APA, 2000) Tanı Ölçütleri Başvuru El Kitabında Majör Depresyon tanı kriterleri içerisinde yas süreci bir dışlanma kriteri iken bu durum DSM-5 (APA, 2013) 'te değiştirilmiş ve yas durumu Majör Depresif Bozukluk için bir dıslanma kriteri olmaktan çıkmıştır. Bazı kritikler bu durumun normal yas sürecinde verilen tepkilerin patolojik olarak değerlendirilmesine yol açacağı yönünde olsa da bazı savunucular da bu durumun yas sürecinde psikolojik yardıma ihtiyacı olanları daha iyi ayrıştırmayı sağlayaca ğını öne sürmektedir (Zisook, Shear ve Kendler, 2007). DSM-5'te ayrıca "Daha İleri Çalışmalar için Durumlar" başlklı bölümde "Kalıı1 Komplike Yas Bozukluğu” adlı bir bölüm açılmıştır. Bu bölüm için önerilen tanı kriterlerini karşılaması için kişinin yakın ilişki içerisinde olduğu birinin kaybını yaşaması gerekmektedir. Kaybın ardından kaybedilen kişiye süreğen bir özlem duyma, yoğun bir keder ve duygusal acı, kaybedilen kişi ve ölüm ile ilgili sürekli meşguliyet şeklinde belirtilerin olduğu günlerin, belirtilerin olmadığı günlere göre daha çok sayıda olması ilk kriter olarak belirlenmiştir. İkinci kriter olarak ölümden sonra yetişkinlerde 12 ay, çocuklarda ise 6 ay boyunca sıralanan belirtilerden en az altısının olduğu günlerin, belirtilerin olmadığı günlere göre daha çok olması ve bu belirtilerin klinik olarak anlamlı bir ölçüde yaşanması belirlenmiştir. Toplamda 12 adet olan bu belirtiler iki ana başlikta toplanmıştır. Birinci kategori Ölüme Verilen Tepkisel Stres kategorisidir. Bu kategori ölümü kabul etmede yaşanan bariz zorluğu (çocuklarda bu durum çocuğun ölümün anlamı ve kalıcılığını kavrayıs kapasitesine bağhdır), kayba inanmama ve duygusal hissizliği, kaybedilen kişi ile ilgili olumlu anıları anlatmakta yaşanan zorluğu, kayı ile ilgili acı ve öfkeyi, kayı ve ölüme dair işlevsel olmayan yorumlamaları (örn, kendini suçlama) ve kaybı hatırlatan şeylerden aşrı kaçınma halini içerir. İkinci kategori Sosyal Bozulma ve Kimlik Bozulması kategorisidir. Bu kategori kaybedilen kişi ile birlikte olabilmek için ölme arzusu duymayı, kaybın ardından diğer kişilere güvenme güçlügüunü, kayıp sonrası yalnız ve diğer insanlardan kopuk hissetmeyi, kaybedilen kişi olmadan hayatın anlamsız ve boş olduğunu hissetmeyi ya da kaybedilen kişi olmadan devam edilemeyeceği inancını, hayattaki role dair karmaşa ya da benlik algısında bozulmayı (örn. kaybedilen kişi ile benliğin bir kısmının da öldüğünü hissetme gibi), kayıptan beri bir şeylerle ilgilenmekte zorluk ya da isteksizlik veya geleceğe dair planlarda zorluğu içerir. Diğer tanı kriterleri bu bozulmaların klinik olarak anlamlı düzeyde strese veya sosyal, mesleki ve diğer önemli işlevsellik alanlarında anlamlı bozulmaya sebep olması ve yas tepkilerinin kültürel, dini ya da yaş ile ilişkili normlara göre orantısız olmasıdır.

\section{Bölümde Yas ve İnkar}

Bölümün başında Ash'in skklkkla telefonuna daldığ dikkat çekmektedir. Ash'in bu davranışının yanlış olduğuna ve bundan rahatsızlık duyduğuna dair Martha Ash'e sklkkla geribildirim vermektedir. Ash'in telefon kullanma alıskanlığını kontrol etmesi, arabayı kullanması ve mola verdiklerinde gidip kahveleri yine Martha'nın alması ilişkilerinde daha aktif tarafin Martha olduğuna dair ipuçları olarak görülebilir. Ash ve Martha'nın geçmiş yaşantılarına dair bilgimiz az olmasına rağmen Ash'in küçüklük 
fotoğrafi üzerine Ash'in anlattı̆̆ı hikayeden Ash'in kardeşi Jack'in çocukken öldüğü anlaşılmaktadır. Ash fotoğrafın çekildiği günün kendisi için garip olduğunu o gün kardeşi Jack'in ölümünden sonra ilk defa ailecek dışarı çıktklarını, kimsenin konuşmadığını ve ertesi gün de annesinin Jack'in tüm foto ğraflarını tavan arasına kaldırdığını anlatmaktadır. Ash annesinin olaylarla böyle başa çıktığını, babası öldüğünde de yine tüm fotoğrafları tavan arasına kaldırdı̆̆ını anlatmaktadır.

Yasa dair bildik lerimiz ile dizideki bilgileri birleştirecek olursak dizide Martha eşini beklenmeyen bir şekilde trafik kazası nedeni ile kaybetmiştir. Literatürdeki bilgiler beklenmeyen, ani ölümlerin komplike yas riskini arttıran faktörlerden biri olduğunu göstermektedir (Rainer, 2013). Cenazede Martha'nın künt bir halde olduğu dikkat çekmektedir. Sarah'nın kendi yas deneyiminde işe yarayan uygulamadan bahsettiği sırada Martha öfkelenmekte ve Sarah'ya şiddetle bağırmaktadır. Cenaze sonrasında Martha'nın kırsaldaki eve dönmüş olduğu görülmektedir. Martha'nın evde Ash ile ilgili izleri gördükçe duygulanması ve Ash'in tavan arasındaki fotoğraflarına bakmak istemesi Martha için yas sürecinin normal seyrinde ilerlediğine dair göstergelerden sayılabilir. Ayrıca Martha'nın yeni taşındıkları evi düzene sokmaya çalışığını, duygusal iniş çıkışlara rağmen, işlevselliğini sürdürmeye çabaladığını söyleyebiliriz. Sarah’nı onu cenazede önerdiği sisteme kaydettiğini öğrendiğinde, Martha'nın Sarah' ya israrla “o öldü” demesi dikkat çekmektedir. Bu cümle de Martha'nın Ash'in ölümünü kabullenmeye çahş̧ı̆̆ının bir işareti olarak yorumlanabilir. Martha uygulamanın Ash olmayacağını söylese de Sarah 'nın ısrarcı olduğu görülmektedir. Martha kusmalarının artması ve hamile olduğunu öğrenmesi ile daha da duygusal bir sürece girmiştir. Kaybettiği kocasından bir çocuğu olacağını öğrenen ve destek almak için ablasına ulaşamayan Sarah bu hassas dönemde sistemdeki Ash'e yazma ihtiyacı duyar. Şiddetle reddettiği uygulamayı kullanma arzusunun bu sürece denk gelmesi Ash'in bir parçasını canlı tutabileceği algısı ve bunun da inkar sürecini harekete geçirmesi ile açıklanabilir. Martha konuşmada ilk olarak uygulamaya "bu sen misin" diye sorar. Yarı inkar durumunda olan Martha'nın bilinç düzeyinde Ash'in öldüğünü kabul ettiği, ama bir yandan da bunu inkar etmeye meyilli olduğu söylenebilir. Bilgisayarda Ash simülasyonu ile konuşmanın Martha'yı duygusal olarak sakinleştirdiğini görürüz. Ablasını aradığında oldukça endişeli olan Martha'nın ablası geri aradığında sakin olduğu görülmektedir. Bu noktada Martha için normal ilerleyen yas sürecinin sekteye uğradığını söylemek yanhış olmaz. Martha'nın sakinleşmesinde Ash'i canh tutma arzusunun kısmen tatmin olmasının ve Ash ile tamamlanmamış meselelerini, doyurulmamış ihtiyaçlarını halledebileceği yeni bir alan açılmış olmasının etkili olmuş olabileceği düşünülmektedir. Martha her ne kadar konuştuğunun simülasyon olduğu gerçeğinin farkında olsa da uygulama gitgide Martha'yı bu gerçekten uzaklaştırmaktadır. Uygulama ticari olarak kişilere daha üst bir uygulamayı satmak amaciyla sürekli bir üst aşamaya vurgu yapmakta, Ash'in sesini duymak veya onu görmek için özlem duyan Martha da kaybettiği Ash'e daha çok yaklaşmak amacıyla uygulamada daha fazlasını istemektedir. Yazışmaların yetmediği noktada, telefonda konuşma ve ardından da sentetik vücut uygulaması Martha için inkarı güçlendirmektedir. Ama inkarı güçlendiren bu ileri uygulamalar aynı zamanda inkarı kırmaya da yardımcı olacaktır. Martha Ash'i şiddetle özlemekte ve yanında olmasını arzulamaktadır. Daha önce de belirtildiği gibi kaybedilen kişiye süreğen bir özlem duyma DSM-5'te Kalıı Komplike Yas Bozukluğu bölümünde bir kriter olarak belirtilmektedir. Martha uygulamayı kullanmaya başladıktan sonra ablasının aramalarını reddeder ve sadece sanal Ash ile vakit geçirmeye başlar. İlk etapta tüm skintılarında ablasını arayan Martha'nın artı ablasının aramalarını reddediyor oluşu zihninin bir tarafinda yaptığı şeyin sağlkssız olduğuna ve ablasının da bu durumu öğrenirse engel olmaya çalısacağına dair farkındalığı olduğuna işaret olarak görülebilir. Martha bir yanıyla başkalarının onu gerçekliğe çekmesine engel olmaya çalışmakta ve sanal Ash'i herkesten saklamaktadır. Martha Ash ile konuşmalarında ona eski anıları anlatır ve onunla sürekli iletişimde kalmaya çalşsr. Buna o kadar çok zaman harcar ki hayata tam anlamıyla karışamaz ve Ash'in sanal varlı̆̆ına saplanıp kalır. Bununla birlikte Martha'nın tam anlamıyla inkar içinde olduğunu da söyleyemeyiz çünkü gerçeklikten kopmamıştır ve sanal Ash ile gerçek Ash arasındaki farkları bulmakta ve dillendirmektedir. Sanal Ash Martha ne isterse onu yapmaktadır, onun 
biricik özellikleri ve geçmişi yoktur. Ash ile bu şekilde bağlantı kuruyor oluşu ama kendini kandırdığının da farkında oluşu git gide Martha'yı rahatsız etmeye başlar. Uygulamada sentetik vücut aşamasına geçmesi ile birlikte Martha iyice durumdan ürkmeye başlamıştır. Gerçek Ash'de ve bir insanda olan küçük ayrıntılar sentetik Ash'de yoktur. Vücudunun ayrntılarında, cinsellik yaşama biçimlerinde Martha onun gerçek Ash olmadığını daha da çok görmeye başlar. Bu Ash spontan değildir, Martha ile kavga etmemektedir, Martha ne derse onu yapmaktadır, uyumamakta ve nefes almamaktadır. Ash'in insana özgü şeyleri yapmaması, robotik davranmas1, Martha'nın bu durumdan ürkmesi ve sinirlenmesi ile işler çı̆̆ıından çımaya başlar. Martha sentetik Ash'in her hareketinde elinde olanın gerçek Ash olmadığının daha çok farkına varmaya başlar ve tekrar tekrar onun Ash olmadığı gerçeği ile yüzleşir. Ablasının aniden onu ziyarete gelmesi ve banyoda erkek kıyafetleri görmesi ile "hayatına devam ediyor olman güzel, her şeyin en güzelini hak ediyorsun" şeklinde Martha'yı normal yas sürecine çekmesi ile Martha sentetik Ash'in yapaylklarına katlanamamaya başlar. Duruma öfkesinin bu olaydan sonra daha da çok arttığı gözlemlenmektedir. Aslında bu öfkenin Elisabeth Kübler Ross'un aşamalarında olduğu gibi gerçekliğin kısmi kabulüne hizmet ettiğini söyleyebiliriz. Gerçek olmadığı için sentetik Ash'e karşı açığa çıkan bir öfke vardır. Sanal Ash ile iletişim kurulan süre boyunca sekteye uğramış olan yas tepkileri yeniden belirmeye başlar. Sonunda Martha sentetik Ash'den kurtulmak ister. Onu bir uçurum kenarına götürür. Onun gerçek olmadığını ve atlamasını istediğini söyler. Bu bile Martha'nın Ash'in gerçek olup olmadığına dair yaptığı bir testtir. Çünkü Ash olsa atlamayı hemen kabul etmeyeceğini, ağlayacağını yalvaracağını söyler. Bunun üzerine sentetik Ash'in ağlayıp yalvarmaya başlaması üzerine Martha'nın çığlı̆̆ını duyarı.

Dizinin son sahnesinde Martha'nın Ash'i tavan arasına kaldırmış olduğunu görürüz. Aslında hikayenin kendi örüntüsü içerisinde bu oldukça anlamlıdır. Çünkü Ash'in annesi de Ash'in kardeşi Jack'in ve Ash'in babasının yas süreci ile başa çıkmak için onlarla ilgili her şeyi tavan arasına kaldırmıştır. Ash ve onu hatrlatan şeylerin sürekli gözünün önünde olması Martha'nın yas sürecini etkilemiş ve ölümü kabul etmesini zorlaştırmıştır. Ash'i tavan arasına kaldırmasının ise Martha'nın hayatına devam etmesine olumlu etkisi olduğu söylenebilir. Zihin yapısı ve evin mimari yapısı birbirine benzetilecek olursa Martha'nın Ash'i evin kullanım ve paylaşım alanından tavan arasına taşıması, zihninde de Ash'i birincil alandan çıkararak hafizasına yerleştirmiş olması ile benzetilebilir. Sevilen bir kişinin kaybından sonra zihnin sürekli kaybedilen kişi ile meşgul olması sk görülen bir durumdur. Bununla birlikte normal yas sürecinde zaman geçtikçe kayıp yaşayan kişi günlük yaşamın rutinine geri dönmekte ve kaybedilen kişi anılardaki yerini almaktadır.

\section{Sonuç}

Ölüm insan yaşamındaki en acı deneyimlerden biridir. Sevilen kişilerin kaybı ve bu süreçle başa çıkmak zaman ve sabır isteyen bir süreçtir. Literatürdeki bilgiler tek bir yas deneyimi olmadığ 1 konusunda nettir. Herkesin yasının içeriği, süresi ve süreci kendisine has olacaktır. Ama ölüm de insan yaşamının doğal bir parçası olarak görüldüğünde, sevilen kişinin kaybı zihinde bir anlam ile bütünleştirildiğinde, kaybedilen kişiye yatırılan enerji zaman içerisinde başka kaynaklara döndüğünde yas sürecinin kişiyi büyüttüğünü de söyleyebiliriz. Dizideki bölüm her ne kadar bilim kurgu tarznda olsa da inkar etmenin yas sürecinde ilerlemeyi yavaşlattığı bir gerçektir. Kaybedilen kişi hiç kaybedilmemiş gibi odasını bozmamak, onun ölümü ile ilgili konuşmalardan ve uyaranlardan kaçmmak yas tutan kişiyi komplike yas sürecine götürebilmektedir. 


\section{Kaynaklar}

American Psychological Association (2013). Publication manual of the American Psychological Association (5. Baskı). Washington, DC:APA.

Bonanno, G. A. (2004). Loss, trauma, and human resilience: Have we underestimated the human capacity to thrive after extremely aversive events? American Psychologist, 59, 20-28.

Bowlby, J. (1973). Attachment and Loss, Vol 2. New York: Basic Books.

Bowlby, J. (1980). Attachment and Loss, Vol 3. New York: Basic Books.

Boyraz, G., Horne, S. G., ve Waits, J. B. (2015). Accepting death as part of life: Meaning in life as a means for dealing with loss among bereaved individuals. Death Studies, 39, 1-11.

Freeman, S. J. (2005). Grief \& Loss: Understanding the Journey. USA: Thomson Brooks/Cole.

Heidegger, M. (1926). Being and Time. New York: State University of New York Press.

Humphrey, G. M. ve Zimpfer, D. G. (2008). Counselling for Grief and Bereavement. London: SAGE publications.

Kübler- Ross, E. (1997). Ölüm ve Ölmek Üzerine. İstanbul: Boyner Holding Yayınlar1.

Mancini, A. D., ve Bonanno, G. A. (2009). Predictors and parameters of resilience to loss: Toward an individual differences model. Journal of Personality, 77, 1805-1832.

Middleton, W., Burnett, P., Raphael, B., ve Martinek, N. (1996). The bereavement response. A cluster analysis. The British Journal of Psychiatry, 169 (2), 167-171.

Neimeyer, R. A., Baldwin, S. A., ve Gillies, J. (2006). Continuing bonds and reconstructing meaning: Mitigating complications in bereavement. Death Studies, 30, 715-738.

Parkes, C., ve Weiss, R. (1983). Recovery from bereavement. New York: Basic Books.

Prigerson, H. G., Horowitz, M. J., Jacobs, S. C., Parkes, C. M., Aslan, M., Goodkin, K., ... Maciejewski, P. K. (2009). Prolonged grief disorder: Psychometric validation of criteria proposed for DSM-V and ICD-11. Plos Medicine, 6(8), 1-12.

Rainer, J. (2013). Life after loss: Contemporary Grief Counseling and Therapy. US: PESI Publishing and Media.

Wong, P., Reker, G. T., ve Gesser, G. (1994). Death Attitude Profile-revised: A multidimensional measure of attitudes toward death. R. A. Neimeyer (Ed.), Death anxiety handbook: Research, instrumentation, and application içinde (s. 121-148). Florence, KY: Taylor \& Francis.

Worden, J. W. (1991). Grief counselling and grief therapy. New York: Springer.

Yalom, I. D. (2008). Staring at the sun: Overcoming the terror of death. San Francisco, CA: Jossey-Bass.

Zisook, S., Shear, K., ve Kendler, K. S. (2007). Validity of the bereavement exclusion criterion for the diagnosis of major depressive episode. World Psychiatry, 6, 102-107. 


\section{Summary \\ The Analysis of the Episode named "Be Right Back" of the TV Series Black Mirror within the Scope of Loss and Denial}

The episode named "Be Right Back" of the TV series Black Mirror is about the effect of Martha's online communication with her dead husband Ash with the help of an application on her bereavement process. Although the aim of the whole series is to show the dark side of the technological developments to the audience, important inferences can be made about the role of denial on the bereavement process. While Martha is in a normal bereavement process after the death of her husband, she started to write to the system that imitates Ash, and then started to talk with Ash on phone. On the latest version of the application Martha bought, a synthetically designed body of Ash came to house. For Martha this process includes both the reunion with her beloved husband Ash and the confrontation with the reality that her synthetic Ash is not real Ash. Although after the loss of a loved one, partial denial might be a part of normal bere avement process, persistence of denial might interrupt the bereavement and complicate it. This theme in the episode was discussed within the scope of the loss of a loved one and the role of denial in the bereavement process.

Key Words: Black Mirror, Loss, Bereavement, Denial 